Tropical Journal of Pharmaceutical Research April 2019; 18 (4): 829-835

ISSN: $1596-5996$ (print); 1596-9827 (electronic)

(C) Pharmacotherapy Group, Faculty of Pharmacy, University of Benin, Benin City, 300001 Nigeria.

\title{
Optimization of extraction of total flavonoids from Drynaria rhizome, and its effect on osteoclast differentiation
}

\author{
Bo Yuan, Fang Yu, WenJi Song, ZhengNan Zhao, HaiDong Liang* \\ Hands and Feet Microsurgery, The Second Hospital of Dalian Medical University, Dalian, 116023, People's Republic of China \\ ${ }^{*}$ For correspondence: Email: lianghddlf@sina.com
}

Sent for review: 13 December 2018

Revised accepted: 25 March 2019

\begin{abstract}
Purpose: To optimize the extraction parameters for total flavonoids of Drynaria rhizome, and determine their effect on osteoclast differentiation and bone resorption in vitro.

Methods: A 5-level 3-factor central composite design was applied to the optimization of extract yield of total flavonoids from Drynaria rhizome. Response Surface Methodology (RSM) design was used to optimize total flavonoids extraction from Drynaria rhizome. The independent factors included extraction temperature (A), extraction time (B) and liquid: solid ratio (C). Moreover, NFATC1, DC-STAMP, cathepsin $K$ and MMP-9 mRNA expressions were determined.

Results: Values obtained were fitted into a second-order polynomial equation with multiple regression analysis using a statistical method. Analysis of variance results indicate that the independent variables influenced total flavonoid extraction from Drynaria rhizome. The optimal conditions for extraction yield were extraction temperature of $75^{\circ} \mathrm{C}$, extraction time of $100 \mathrm{~min}$, and liquid: solid ratio of 107:1. The yield of $5.38 \pm 0.62 \%$ was consistent with these optimized conditions, which was an indication of the accuracy of the model. Experiments revealed that total flavonoids from Drynaria rhizome regulated the expression levels of NFATC1, DC-STAMP, cathepsin K and MMP-9 mRNA

Conclusion: This study has successfully optimized the extraction yield of total flavonoids from Drynaria rhizome. The total flavonoids inhibit osteoclast differentiation and bone resorption. Thus, they may be beneficial in the treatment of bone diseases.
\end{abstract}

Keywords: Flavonoids, Drynaria rhizome, RSM, Osteoclast differentiation, Bone resorption

\begin{abstract}
This is an Open Access article that uses a fund-ing model which does not charge readers or their institutions for access and distributed under the terms of the Creative Commons Attribution License (http://creativecommons.org/licenses/by/4.0) and the Budapest Open Access Initiative (http://www.budapestopenaccessinitiative.org/read), which permit unrestricted use, distribution, and reproduction in any medium, provided the original work is properly credited.
\end{abstract}

Tropical Journal of Pharmaceutical Research is indexed by Science Citation Index (SciSearch), Scopus, International Pharmaceutical Abstract, Chemical Abstracts, Embase, Index Copernicus, EBSCO, African Index Medicus, JournalSeek, Journal Citation Reports/Science Edition, Directory of Open Access Journals (DOAJ), African Journal Online, Bioline International, Open-J-Gate and Pharmacy Abstracts

\section{INTRODUCTION}

Drynaria fortunei (Kunze) J.Sm. (Polypodiaceae) is a fern that grows in South China. In Traditional Chinese Medicine (TCM), the rhizomes of this fern are used for treating broken bones and osteoporosis [1,2]. Studies have demonstrated that Drynaria fortunei contains flavonoids, triterpenes and phenylpropanoids [3,4].
In in vitro experiments on osteoblastic cells, Drynaria fortune has showed antiresorptive properties [5]. Moreover, it has been reported that oral administration of Drynaria fortunei extracts to mice enhanced bone mineral density [6]. In traditional system of medicine, Drynaria fortune rhizome has been employed for treating hyperlipidemia, inflammation, 
rheumatism, and arteriosclerosis, as well as skin diseases such as leprosy, malignant furuncle, and gangrene [7-10].

Response surface methodology (RSM) is a procedure in statistics and mathematics which is employed for optimizing multifactorial processes, and for expressing the effect of multiple factors on the response. Response surface methodology is an effective and reliable method for the prediction of optimum conditions for maximization or minimization of different independent factors, and the association between responses and independent variables. In this process, factors that make significant impacts on prediction can be identified through the use of parameter estimate [11]. Response surface methodology (RSM) is applied for process optimization in various aspects of food formulations [12].

The aim of the current was to optimize the individual and interactive effects of extraction temperature, extraction duration and liquid: solid ratio on the yield of flavonoid extract from Drynaria rhizome by RSM, and to investigate the effect of the extract on differentiation of osteoclasts in RANKL-treated RAW 264.7 cell line.

\section{EXPERIMENTAL}

\section{Material and methods}

Drynaria rhizome was bought from Merro Pharmaceutical Co. Ltd (DaLian, China) and identified by expert Xu.

\section{Reflux extraction}

Drynaria rhizome (50 g) was extracted with $70 \%$ ethanol solution at different temperatures and for different durations. Each extract was evaporated to a volume of $150 \mathrm{~mL}$ at low pressure at $50{ }^{\circ} \mathrm{C}$. The effect of temperature, extraction time and liquid: solid ratio as tested variable parameters were evaluated by examining extraction yield.

\section{Experimental design}

A three-factor and five-level central composite design (CCD) with RSM was used to ascertain how the independent variables could be optimally combined. The variables investigated were extraction time, extraction temperature, and liquid: solid ratio. Flavonoid yield was considered as the dependent variable. These factors were selected on the basis of prior data from singlefactor studies. In the experimental design, twenty runs were needed for a CCD of 3 independent variables at 3 levels. The design of experiments is shown in Table 1.

\section{Cell culture}

RAW 264.7 cell line was got from American Type Culture Collection (ATCC, Rockville, USA). The cells were cultured in high glucose DMEM containing $10 \%$ FBS and $1 \%$ penicillin/streptomycin.

\section{Osteoclast differentiation}

The cells were seeded at a density of $5 \times 10^{3}$ cells/well in 24-well plates. After 5 days, they were divided into five groups: control, RANKL (50 $\mathrm{ng} / \mathrm{mL})$, RANKL $(50 \mathrm{ng} / \mathrm{ml})$ + total flavonoids extract of Drynaria rhizome (10 mg/L), RANKL $(50 \mathrm{ng} / \mathrm{mL})+$ total flavonoid extract of Drynaria rhizome $(20 \mathrm{mg} / \mathrm{L})$, and RANKL $(50 \mathrm{ng} / \mathrm{mL})+$ total flavonoid extract of Drynaria rhizome (30 $\mathrm{mg} / \mathrm{L})$. The cultured cells were subjected to fixation and stained with TRAP. Osteoclasts were recognized as cells that were positively stained by TRAP, with the presence of at least three nuclei.

\section{Real-time polymerase chain reaction (PCR) analysis}

Table 1: Genes used and their sequences

\begin{tabular}{ll}
\hline Gene & Sequence \\
\hline NFATc1 & Forward, 5'- \\
& GGAGAGTCCGAGAATCGAGAT-3'; \\
& Reverse, 5'- \\
& TTGCAGCTAGGAAGTACGTCT-3' \\
DC- & Forward, 5'- \\
STAMP: & TCCTCCATGAACAAACAGTTCCA-3'; \\
& Reverse, 5'- \\
& AGACGTGGTTTAGGAATGCAGCTC-3' \\
Cathepsin & Forward, 5'- \\
K: & ACGAGAAAGCCCTGAAGA-3'; \\
& Reverse, 5'- \\
& TGTAAAATGGAAAGATGCC-3' \\
MMP-9: & Forward, 5'- \\
& TGAATAAAGACGACATAGACGGCAT- \\
& 3'; \\
& Reverse, 5'- \\
& GGTAGTGGGACACATAGTGGGAG-3' \\
\hline
\end{tabular}

The extraction of total cellular RNA was carried out using Trizol reagent. The extracted RNA was converted to cDNA through reverse transcription with appropriate reverse transcription kit (Toyobo ReverTra Ace qPCR RT Master Mix, Japan). The RT-PCR was performed using SYBR® Green RT-PCR Master Mix (Toyobo, Japan), and reaction products were determined using StepOnePlus Real-time PCR system (Thermo Fisher, USA). RT-PCR was carried out under the following steps and conditions: $95{ }^{\circ} \mathrm{C}$ for $1 \mathrm{~min}$, 
40 cycles of $95{ }^{\circ} \mathrm{C}$ for $15 \mathrm{~s}, 60{ }^{\circ} \mathrm{C}$ for $15 \mathrm{~s}$, and $72{ }^{\circ} \mathrm{C}$ for $45 \mathrm{~s}$, followed by melting curve analysis. The primer sequences used are shown in Table 1.

\section{Statistical analysis}

The results are shown as mean \pm SEM. Statistical analysis was performed using ANOVA followed by Tukey's post-test. Comparison of the two groups was carried out with Student's $t$-test. GraphPad Prism software was employed for the statistical analysis. Values of $p<0.05$ were assumed to indicate statistical significance of differences.

\section{RESULTS}

\section{Effect of variables on extraction yield}

Extraction temperature, extraction duration and liquid: solid ratio were selected as independent variable parameters. Figure 1 reveals that extraction yield was enhanced by temperature increases to a certain extent. When extraction temperature exceeded $80{ }^{\circ} \mathrm{C}$, extract yield was $5.42 \%$, but it did not change subsequently.

Figure 2 reveals that extraction yield increased with increase in extraction time up to some extent. When extraction time exceeded $105 \mathrm{~min}$, extraction yield was $5.49 \%$, but it did not change subsequently.

Figure 3 shows that extraction yield increased initially with increases in liquid: solid ratio. However, when the liquid: solid ratio exceeded 110:1, extraction yield was $5.31 \%$. No further changes were seen beyond this point.

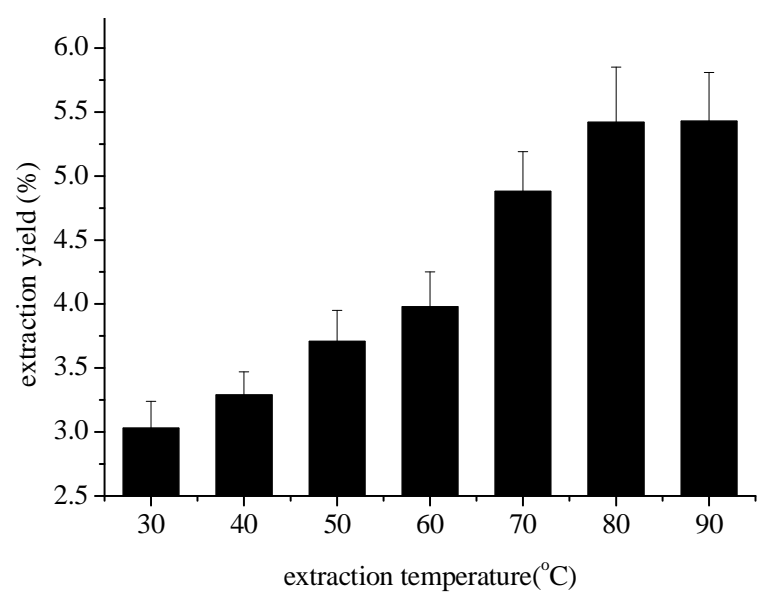

Figure 1: Effect of extraction temperature on yield of total flavonoids from Drynaria rhizome

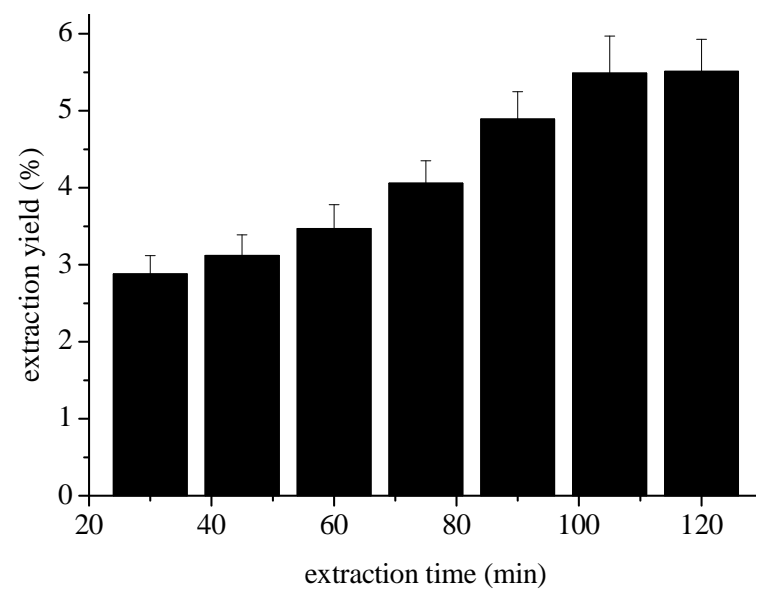

Figure 2: Effect of extraction time on yield of total flavonoids from Drynaria rhizome

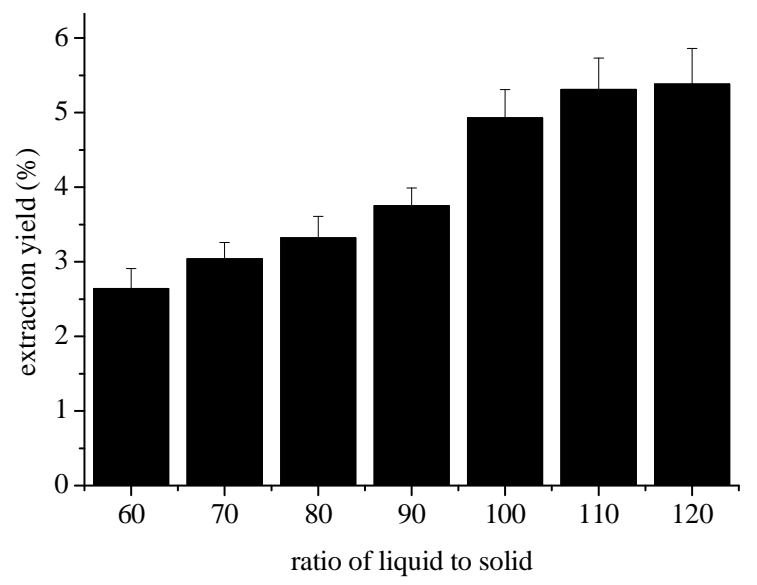

Figure 3: Effect of liquid: solid ratio on yield of total flavonoids from Drynaria rhizome

\section{Optimization of factors using central composite design}

The central composite design and extraction yields are shown in Table 2. Design-Expert software was used for the development of response surface models. The results of ANOVA in respect of response surface quadratic model are shown in Table 3 . This model was highly significant, based on $\mathrm{F}$ - and low probability values of 15.84 and $p<0.0001$, respectively. The model terms $A, C, A C, A^{2}$ and $C^{2}$ were significant, and $A C$ implied a marked association between extraction temperature and liquid: solid ratio. The high $R^{2}(0.9345)$ meant a significant agreement between the predicted and experimental values. Equation 1 shows the quadratic model for predicting the extraction yield.

$R=\quad+5.19+0.34^{*} A+1.498 E-003^{*} B+$ $0.35^{\star} C+0.049^{\star} A A^{*} B-0.28^{*} A^{*} C-0.046^{*} B^{*} C-$ $0.13^{\star} A 2-0.014^{*} B 2-0.13^{*} C 2$ 
Table 2: Box-Behnken design (BBD) showing A, B and $C$ responses to changes in conditions of extraction

\begin{tabular}{lcccc}
\hline Run & $\begin{array}{c}\text { A: Extraction } \\
\text { temperature }\left({ }^{\circ} \mathbf{C}\right)\end{array}$ & $\begin{array}{c}\text { B: Extraction } \\
\text { time }(\mathbf{m i n})\end{array}$ & $\begin{array}{c}\text { C: Ratio of liquid } \\
\text { to solid }\end{array}$ & $\begin{array}{c}\text { R: Extraction } \\
\text { yield (\%) }\end{array}$ \\
\hline 1 & -1.00 & -1.00 & -1.00 & 3.75 \\
2 & 1.00 & -1.00 & -1.00 & 5.02 \\
3 & -1.00 & 1.00 & -1.00 & 3.72 \\
4 & $1.00(80)$ & 1.00 & $-1.00(90)$ & 5.22 \\
5 & $-1.00(60)$ & -1.00 & 1.00 & 5.24 \\
6 & 1.00 & $-1.00(75)$ & 1.00 & 5.44 \\
7 & -1.00 & 1.00 & 1.00 & 5.06 \\
8 & 1.00 & $1.00(105)$ & $1.00(110)$ & 5.42 \\
9 & $-1.68(53.2)$ & $0.00(90)$ & $0.00(100)$ & 4.5 \\
10 & $1.68(86.8)$ & 0.00 & 0.00 & 5.31 \\
11 & $0.00(70)$ & $-1.68(64.8)$ & 0.00 & 5.22 \\
12 & 0.00 & $1.68(115.2)$ & 0.00 & 5.25 \\
13 & 0.00 & 0.00 & $-1.68(83.2)$ & 4.52 \\
14 & 0.00 & 0.00 & $1.68(116.8)$ & 5.3 \\
15 & 0.00 & 0.00 & 0.00 & 5.2 \\
16 & 0.00 & 0.00 & 0.00 & 5.19 \\
17 & 0.00 & 0.00 & 0.00 & 5.18 \\
18 & 0.00 & 0.00 & 0.00 & 5.16 \\
19 & 0.00 & 0.00 & 0.00 & 5.18 \\
20 & 0.00 & 0.00 & 0.00 & 5.21 \\
\hline
\end{tabular}

Table 3: Regression coefficient $(\beta)$, coefficient of determination $\left(R^{2}\right)$ and F-test values of the predicted second order polynomial models (BBD) for total flavonoid extraction from Drynaria rhizome

\begin{tabular}{|c|c|c|c|c|c|c|}
\hline Source & $\begin{array}{l}\text { Sum of } \\
\text { squares }\end{array}$ & df & $\begin{array}{c}\text { Mean } \\
\text { square }\end{array}$ & $\mathbf{F}$ & $\begin{array}{c}P \\
\text { Prob }>F\end{array}$ & \\
\hline Model & 4.36 & 9 & 0.48 & 15.84 & $<0.0001$ & Significant \\
\hline $\begin{array}{l}\text { A-Extraction } \\
\text { temp. }{ }^{\circ} \mathrm{C}\end{array}$ & 1.61 & 1 & 1.61 & 52.7 & $<0.0001$ & \\
\hline $\begin{array}{l}\text { B-Extraction } \\
\text { time (min) }\end{array}$ & 3.06E-05 & 1 & 3.06E-05 & $1.00 \mathrm{E}-03$ & 0.9754 & \\
\hline $\begin{array}{l}\text { C-liquid: } \\
\text { solid }\end{array}$ & 1.66 & 1 & 1.66 & 54.27 & $<0.0001$ & \\
\hline$A B$ & 0.019 & 1 & 0.019 & 0.62 & 0.4488 & \\
\hline$A C$ & 0.61 & 1 & 0.61 & 19.96 & 0.0012 & \\
\hline $\mathrm{BC}$ & 0.017 & 1 & 0.017 & 0.56 & 0.4717 & \\
\hline $\mathrm{A}^{\wedge} 2$ & 0.25 & 1 & 0.25 & 8.05 & 0.0176 & \\
\hline $\mathrm{B}^{\wedge} 2$ & 2.85E-03 & 1 & 2.85E-03 & 0.093 & 0.7665 & \\
\hline$C^{\wedge} 2$ & 0.24 & 1 & 0.24 & 7.83 & 0.0188 & \\
\hline SD & & \multicolumn{2}{|r|}{0.17} & \multicolumn{2}{|c|}{$R^{2}$} & 0.9345 \\
\hline Mean & & \multirow{2}{*}{\multicolumn{2}{|c|}{$\begin{array}{c}5 \\
35\end{array}$}} & \multicolumn{2}{|c|}{ Adjusted $\mathrm{R}^{2}$} & 0.8755 \\
\hline Coeff. var (\%) & & & & \multicolumn{2}{|c|}{ Predicted $R^{2}$} & 0.5047 \\
\hline Precision & & \multicolumn{2}{|r|}{$\begin{array}{c}3.5 \\
2.31\end{array}$} & \multicolumn{2}{|c|}{ Precision adequacy } & 11.844 \\
\hline
\end{tabular}

Figure 4 (I) shows the 3-dimensional surface plots between each pair of independent variables when the $3^{\text {rd }}$ variable was fixed. These plots reveal the most critical variables in total flavonoids extraction from Drynaria rhizome were liquid: solid ratio and temperature. When liquid: solid was constant, extract yield was rapidly enhanced as temperature was raised. In contrast, the duration of extraction did not have much impact on the yield of total flavonoids from Drynaria rhizome.

Figure 4 (II) shows 3-dimensional graphic surface and contour plots of combined effects of temperature and liquid: solid ratio on yield level of total flavonoids. The plots were generated from two-variable responses at fixed middle status of the $3^{\text {rd }}$ variable. A strong association was found between the two variables, as revealed from the contour and shape of the plots. The yield of total flavonoids was high in the temperature range of $60-80{ }^{\circ} \mathrm{C}$, and liquid: solid ratio in the range of 90:1 - 110:1. This demonstrates that these two variables had significant influence on the yield of total flavonoids, which is consistent with the findings shown in Table 2.

Figure 4(III) shows the influence of duration of extraction and liquid: solid ratio on total flavonoid yield (Y). The yield was rapidly enhanced by increasing liquid: solid ratio, but increased at a slow rate in response to increasing duration of extraction. 


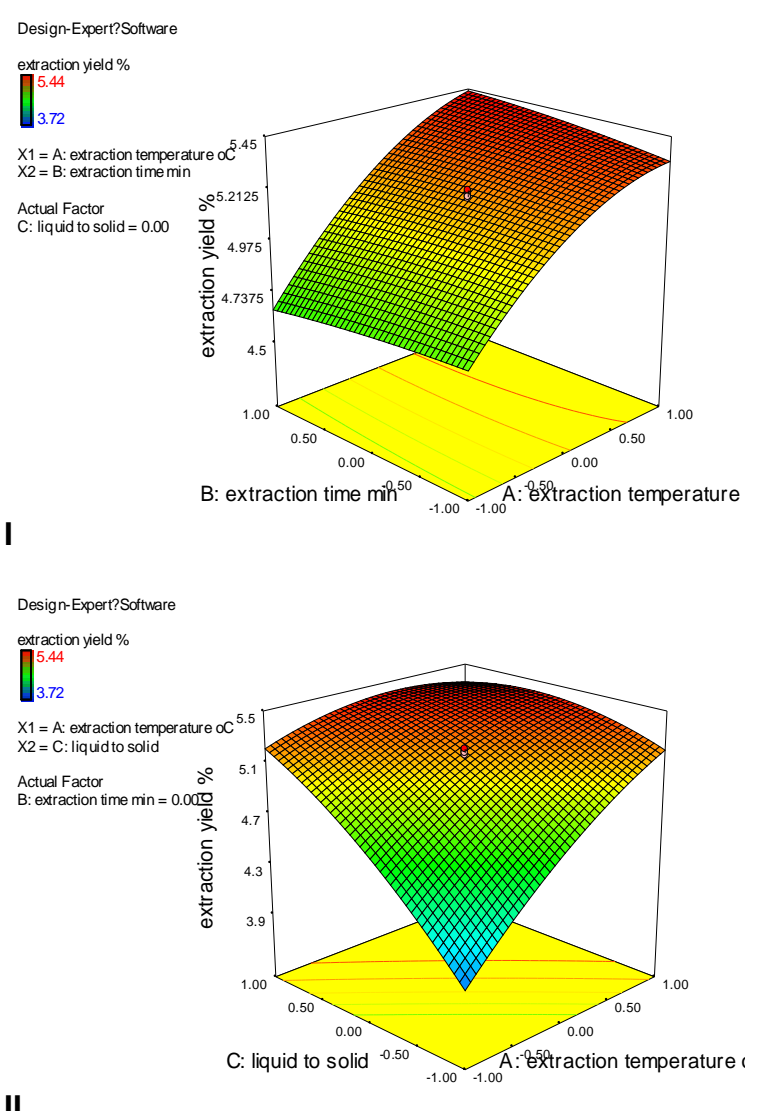

Figure 4: Response surface and contour plots showing the interaction effects of (I) A and B, (II) A and $C$ on the extraction yield of total flavonoids from Drynaria rhizome. A: extraction temperature; B: extraction time; C:liquid: solid ratio

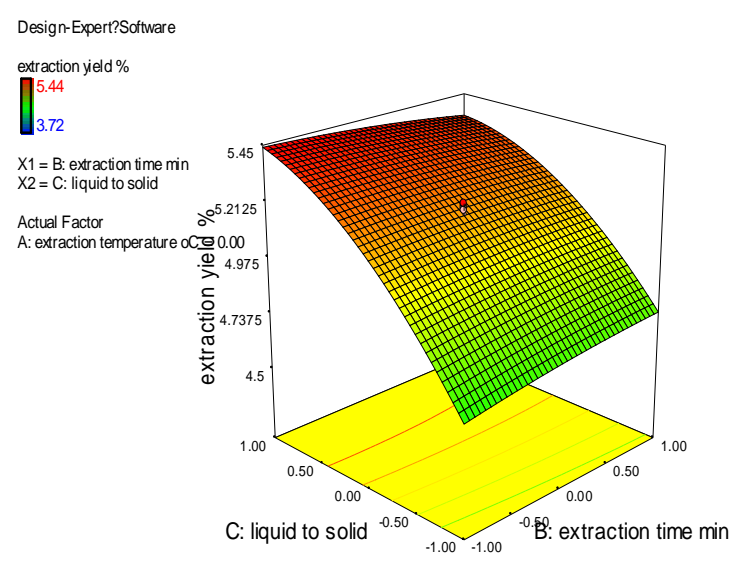

Figure 5: Response surface and contour graphs depicting the influence of interaction of $B$ and $C$ on total flavonoid yield from Drynaria rhizome. B: extraction time; C: liquid: solid ratio

\section{Model validation}

The Design-Expert 9 predicted total flavonoid yield of $5.46 \%$, which was very close to actual mean extract yield of $5.38 \pm 0.62 \%$ under the software-suggested optimum conditions. The closeness of the predicted and actual yields point to the reliability of the parameter optimization. The optimal conditions for determining extraction yield were extraction temperature of $75{ }^{\circ} \mathrm{C}$, extraction time of $100 \mathrm{~min}$, and liquid: solid ratio of $107: 1$.

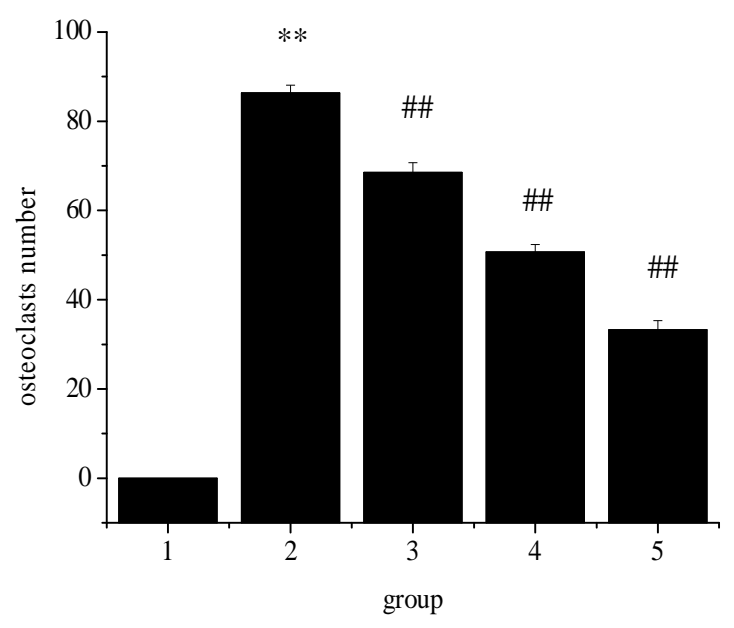

Figure 6: Effect of total flavonoids from yield rhizome on osteoclasts number. 1: control; 2: RANKL (50 $\mathrm{ng} / \mathrm{mL})$; 3: RANKL $(50 \mathrm{ng} / \mathrm{mL})+$ total flavonoid extract of Drynaria rhizome (10 mg/L); 4: RANKL (50 ng/mL) + total flavonoid extract of Drynaria rhizome $(20 \mathrm{mg} / \mathrm{L})$; 5: RANKL $(50 \mathrm{ng} / \mathrm{mL})+$ total flavonoid extract of Drynaria rhizome (30 mg/L)

\section{Effect of total flavonoids of Drynaria rhizome on osteoclast differentiation in RANKL- stimulated RAW 264.7}

RAW 264.7 cells were treated with RANKL and various concentrations of total flavonoid extract of Drynaria rhizome (10,20 and $30 \mathrm{mg} / \mathrm{L})$. As shown in Figure 6, total flavonoid extract of Drynaria rhizome $(10,20$ and $30 \mathrm{mg} / \mathrm{L})$ dosedependently inhibited the differentiation of osteoclast.

\section{Effect of total flavonoids of Drynaria rhizome on osteoclast differentiation-related gene expressions in RANKL-stimulated RAW 264.7}

As shown in Figure 7, NFATC1, DC-STAMP, cathepsin K and MMP-9 mRNA expression levels were markedly downregulated, when compared with corresponding values in control group. Treatment with total flavonoid extract of Drynaria rhizome (10, 20 and $30 \mathrm{mg} / \mathrm{L})$ dose-dependently increased NFATc1, DC-STAMP, cathepsin $\mathrm{K}$ and MMP-9 mRNA expression levels. 


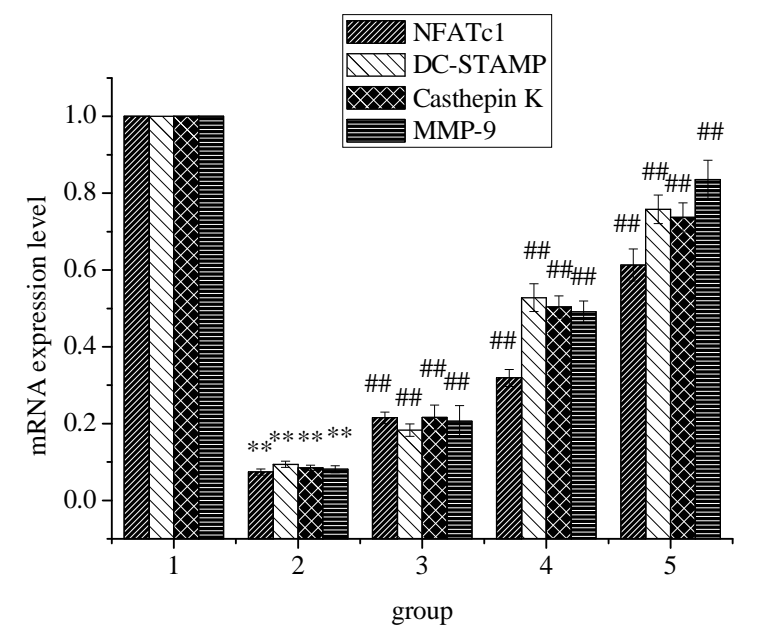

Figure 7: Effect of total flavonoids from Drynaria rhizome on NFATc1, DC-STAMP, cathepsin K and MMP-9 mRNA expression levels. 1: control; 2: RANKL $(50 \mathrm{ng} / \mathrm{mL}) ; 3$ : RANKL $(50 \mathrm{ng} / \mathrm{mL})+$ total flavonoid extract of Drynaria rhizome (10 mg/L); 4: RANKL (50 $\mathrm{ng} / \mathrm{mL})+$ total flavonoid extract of Drynaria rhizome (20 mg/L); 5: RANKL (50 ng/mL) + total flavonoid extract of Drynaria rhizome (30 mg/L)

\section{DISCUSSION}

The closeness of the predicted and actual yields of total flavonoids point to the reliability of the parameter optimization. Osteoporosis is one of the diseases treated with the use of TCM [13]. Indeed, Drynaria fortunei has been employed for centuries as therapy for osteoporosis [14]. Studies on ovariectomized rat model have shown that osteopractic total flavone enhanced their bone mineral density and bone histomorphometry [15]. Osteoclasts are important in bone resorption and skeletal development [16]. Moreover, osteoclasts control the differentiation of osteoblasts, enhance the mobilization of hematopoietic stem cells from bone marrow to the bloods, and take part in immune response [17].

The results of the present study showed that total flavonoids extracted from Drynaria rhizome dosedependently decreased RANKL-induced TRAPpositive osteoclast number. Results from RTPCR revealed that the total flavonoid extract of Drynaria rhizome may affect the mRNA expressions of osteoclast differentiation- related genes NFATc1 and DC-STAMP mRNA. In addition, RT-PCR results indicated that the total flavonoid extract may affect the mRNA expression levels of osteoclast bone absorption activity-related genes cathepsin K and MMP-9. These results suggest that total flavonoids from Drynaria rhizome may decrease osteoclasts bone resorption activity.

\section{CONCLUSION}

The optimization of parameters for total flavonoid extraction from Drynaria rhizome in the present work is reliable. This study has demonstrated that total flavonoid extract of Drynaria rhizome dose-dependently regulate RANKL-induced TRAP-positive osteoclast number. In addition, total flavonoids from Drynaria rhizome may change mRNA expression levels of osteoclast differentiation-related genes NFATc1 and DCSTAMP and mRNA expression levels of osteoclast bone resorption activity-related genes cathepsin K and MMP-9 mRNA. These results indicate that total flavonoid extract of Drynaria rhizome inhibits osteoclast differentiation and bone resorption. This finding is beneficial to bone regeneration and merits clinical application.

\section{DECLARATIONS}

\section{Acknowledgement}

The authors thank Science Work Support of DaLian Medical University for supporting this study.

\section{Conflict of Interest}

No conflict of interest associated with this work.

\section{Contribution of Authors}

The authors declare that this work was done by the authors named in this article and all liabilities pertaining to claims relating to the content of this article will be borne by them.

\section{Open Access}

This is an Open Access article that uses a funding model which does not charge readers or their institutions for access and distributed under the terms of the Creative Commons Attribution License (http://creativecommons.org/licenses/by/ 4.0) and the Budapest Open Access Initiative (http://www.budapestopenaccessinitiative.org/rea d), which permit unrestricted use, distribution, and reproduction in any medium, provided the original work is properly credited.

\section{REFERENCES}

1. Ma KC, Zhu TY, Liu XR, Liu WZ. Promoting effects of Rhizoma Drynariae on the calcification of cultivated chick embryo bone primordium. Chin. J. Chin. Mat. Med., 1995; 20:178-180. 
2. Sun JS, Lin CY, Dong GC, Sheu SY, Lin FH, Chen $L T$, Wang YJ. The effect of Gu-Sui-Bu (Drynaria fortuneiJ.Sm) on bone cell activities. Biomaterials, 2002; 23: 3377-3385.

3. Wang $X L$, Wang NL, Zhang $Y$, Gao $H$, Pang $W Y$, Wong MS, Zhang G, Qin L, Yao XS. Effects of eleven flavonoids from the osteoprotective fraction of Drynaria fortune (Kunze) J.Sm. on osteoblastic proliferation using an osteoblast-like cell line. Chem. Pharm. Bull., 2008; 56: 46-51.

4. Liang YH, Ye M, Zhang LZ, Li HF, Han J, Wang BR, Guo $D A$. Two new phenolic acids from Drynariae Rhizoma. Acta Pharm. Sin., 2010; 45: 874-878.

5. Jeong JC, Lee JW, Yoon $\mathrm{CH}$, Lee YC, Chung KH, Kim MG, Kim CH. Stimulative effects of Drynariae Rhizoma extracts on the proliferation and differentiation of osteoblastic MC3T3-E1 cells. J Ethnopharmacol, 2005; 96: 489-495.

6. Wong RW, Rabie AB. Systemic effect of crude extract from rhizome of Drynaria fortunei on bone formation in mice. Phytother Res, 2006; 20: 313-315.

7. Shi XC. Chinese-English Terminology of Traditional Chinese Medicine. Hunan Science Publishing Co, China 1983; pp. 71-98.

8. Pharmacopoeia Commission, 2005. Pharmacopoeia Commission of People Republic of China, Vol. 1. Chemical Industry Press, China, pp. 179-180.

9. Chang HC, Gupta SK, Tsay HS. Working with ferns: Issues and applications. Part 4. Studies on folk medicinal fern: an example of "Gu-Sui-Bu". Springer, USA (2010) pp. 285-304.
10. Nanjing University of Traditional Chinese Medicine Dictionary of Chinese Materia Medica (2nd edition), Shanghai Science and Technology Publishing House, Shanghai(2006) Zhong Yao Da Ci Dian p. 2329.

11. Mehmood T, Ahmad A, Ahmed A, Ahmed Z. Optimization of olive oil based $O / W$ nanoemulsions prepared through ultrasonic homogenization: $A$ response surface methodology approach. Food Chem, 2017; 229:790796.

12. Park KM, Sung H, Choi SJ, Choi YJ, Chang PS. Doublelayered microparticles with enzyme-triggered release for the targeted delivery of water-soluble bioactive compounds to small intestine. Food Chem, 2014; 161: 53-59.

13. Wang $X$, Zhen L, Zhang G, Wong MS, Qin L, Yao X. Osteogenic effects of flavonoid aglycones from an osteoprotective fraction of Drynaria fortunei-an in vitro efficacy study. Phytomedicine, 2011; 18 (10): 868-872.

14. Sun JS, Lin CY, Dong GC, Sheu SY, Lin FH, Chen LT. The effect of GuSuiBu (Drynariae rhizoma) on bone cell activities. Biomaterials, 2002; 23: 3377-3385.

15. Xie YM, Ju DH, Zhao JN. Effect of osteopractic total flavone on bone mineral density and bone histomorphometry in ovariectomized rats. Zhongguo Zhong Yao Za Zhi, 2004; 29: 343-346.

16. Teitelbaum SL, Ross FP. Genetic regulation of osteoclast development and function. Nat. Rev. Genet., 2003; 4: 638-649.

17. Boyce BF, Yao Z, Xing L. Osteoclasts have multiple roles in bone in addition to bone resorption. Crit. Rev. Eukaryot. Gene Expr., 2009; 19: 171-180. 